\title{
An isolated Posterolateral corner injury with rotational instability and hypermobile lateral meniscus: a novel entity
}

\author{
Kazumi Goto ${ }^{1}$, Victoria Duthon ${ }^{1}$ and Jacques Menetrey ${ }^{1,2^{*}}$
}

\begin{abstract}
Purpose: Although complete tear of the knee posterolateral corner (PLC) commonly occurs in combination with other knee ligamentous injuries, the incidence of isolated PLC injury was reported only 28\% and overlooked in many cases. Nevertheless, an isolated PLC injury does not only provoke posterolateral instability, but also may be associated to hypermobile lateral meniscus. This study aims at showing the characteristics of isolated PLC injuries and to alert potential overlooked cases by describing their arthroscopic findings and clinical characteristics.

Methods: Seventy-one patients with a clinically proven isolated PLC injury who underwent knee arthroscopy were included in this study. Pre-operative symptoms and clinical signs at examination were recorded: Pain at the posterolateral aspect, feelings of instability, catching, locking; and for clinical signs: McMurray test, varus stress test in extension and at $30^{\circ}$ of flexion, posterolateral drawer test at $30^{\circ}$ and $80^{\circ}$, dial test at $30^{\circ}$ and $80^{\circ}$ of flexion. In terms of arthroscopic findings, systematic meniscal stability was performed to evaluate the presence of hypermobile lateral meniscus, "lateral drive through test" was also recorded in all cases.
\end{abstract}

Results: Positive Lateral Drive through test was found in 69 patients (95.8\%). Hypermobile lateral meniscus was seen in all patients.

Conclusions: Hyper mobile lateral meniscus was concomitant with all isolated PLC injuries in our case series. As the typical arthroscopic characteristic, lateral drive through test positive were seen in 95.8\%. In order to prevent overlooking this concomitant pathology, meticulous arthroscopic observation is crucial.

Level of evidence: Level IV.

Keywords: Posterolateral corner, Hypermobile lateral meniscus, Rotational laxity, Popliteomeniscal fascicle

\section{Background}

The posterolateral corner (PLC) of the knee is the main restraint to varus forces of the tibia relative to the femur [3]. In spite of this important function, there is still a limited understanding of the structures, biomechanics, and treatment option $[4,7,25]$. Stabilizers of the PLC include the lateral collateral ligament (LCL), the popliteus tendon (PT), the popliteofibular ligament (PFL),

\footnotetext{
* Correspondence: Jacques.menetrey@hirslanden.ch

${ }^{1}$ Centre for Sports Medicine and Exercise, Swiss Olympic Medical Center, Hirslanden Clinique La Colline, Chemin Thury 7 A, 1206 Geneve, Switzerland ${ }^{2}$ University Hospital of Geneva, Geneva, Switzerland
}

and popliteomeniscal fascicles (PMFs) [37]. The PMFs consists of 3 fascicles: anteroinferior, posterosuperior, and posteroinferior [1], which play a role in rotational knee stability and stabilize the lateral meniscus [34, 35]. Isolated posterolateral laxity lesions, as classified Fanelli and Larson classification type A - B (Table 1) [8] or Hughston classification grade I/II (Table 2) [15], have been regarded as rare pathology since PLC injuries are usually associated with anterior cruciate ligament (ACL) or posterior cruciate ligament (PCL) injury, and the incidence of isolated lesion was reported up to $12-28 \%$ of all PLC injuries [12, 29]. Therefore, isolated PLC injuries

\section{Springer Open}

() The Author(s). 2020 Open Access This article is licensed under a Creative Commons Attribution 4.0 International License, which permits use, sharing, adaptation, distribution and reproduction in any medium or format, as long as you give appropriate credit to the original author(s) and the source, provide a link to the Creative Commons licence, and indicate if changes were made. The images or other third party material in this article are included in the article's Creative Commons licence, unless indicated otherwise in a credit line to the material. If material is not included in the article's Creative Commons licence and your intended use is not permitted by statutory regulation or exceeds the permitted use, you will need to obtain permission directly from the copyright holder. To view a copy of this licence, visit http://creativecommons.org/licenses/by/4.0/. 
Table 1 The Fanelli and Larson classification: classification of damage in posterolateral structures

\begin{tabular}{lll}
\hline Classification & Scale of damage & Damaged structure \\
\hline Type A & $10^{\circ}$ increase in external rotation of the tibia & $\mathrm{PFL}$, popliteus tendon \\
Type B & $10^{\circ}$ increase in external rotation of the tibia & $\mathrm{PFL}$, popliteus tendon \\
& Slight varus relaxation $(5-10 \mathrm{~mm}$ increase in varus load test) & $\mathrm{LCL}$ \\
Type C & $10^{\circ}$ increase in external rotation of the tibia & $\mathrm{PFL}$, popliteus tendon \\
& Slight varus relaxation $(>10 \mathrm{~mm}$ increase in varus load test) & $\mathrm{LCL}$, capsule avalusion, cruciate ligament
\end{tabular}

PFL popliteofibular ligament, LCL lateral collateral ligament

should be overlooked in many cases $(50-76 \%)[23,24$, 29,37 , and this under-recognition may potentially lead to persistent knee posterolateral pain and/or instability sensation [22]. In addition, the post-traumatic disruption of PMFs near the PT may provoke hypermobile lateral meniscus $[11,20,34]$. The hypermobile lateral meniscus may cause pain in the lateral compartment of the knee and mechanical symptoms such as catching, locking and giving way [29]. Apparently, these two pathologies are not independent of each other and may likely exist concomitantly. This study aims at showing the characteristics of isolated PLC injuries defined as type B or grade I/ II injury by stating clinical presentation, clinical examination, imaging and arthroscopic findings. The hypothesis of this study was that symptomatic isolated PLC injuries are frequently combined with hypermobile lateral meniscus.

\section{Methods}

This study used a retrospective case series design, approved by our institutional review board. Between 2015 and 2019, 204 patients diagnosed as PLC injury underwent surgical treatment in our institution. Of these patients, 71 patients (35 males and 36 females, 72 knees) were matching the inclusion criteria of this study which was to have been diagnosed as isolated type B or grade I/II PLC injury clinically. Exclusion criteria included asymptomatic patients, concomitant knee ligament injury, other meniscal lesion, concomitant chondral lesion, knee dislocation, previous PLC injury, previous history of lateral meniscal lesion, and prior trauma around the knee. All data were collected and analyzed retrospectively.

Table 2 The Hughston classification: classification of posterolateral instability assessed by varus instability

\begin{tabular}{lll}
\hline Classification & Varus instability & PCL injury \\
\hline Grade I & $0-5 \mathrm{~mm}$ & Intact $P C L$ \\
Grade II & $5-10 \mathrm{~mm}$ & Intact $\mathrm{PCL}$ \\
Grade III & $>10 \mathrm{~mm}$ (soft endpoint) & PCL rupture
\end{tabular}

$P C L$ posterior cruciate ligament

\section{Mechanism of injury}

We systematically recorded the mechanism of injury when the patient was capable of recollecting it.

\section{Physical examination}

First of all, the physical examination was preceded by careful history taking in every case. Typical symptoms, including history of posterolateral pain, medial or lateral joint line pain, and sensation of instability, were all recorded in our data base. The presence of pain or discomfort by palpation of the joint line was also reported especially around the hiatus popliteus. Grinding and McMurray test [6] were routinely performed. In addition to a comprehensive physical examination of the knee, the following three tests were systematically performed: The varus stress test [21] was performed at both $0^{\circ}$ and $30^{\circ}$ of knee flexion in supine position. The posterolateral drawer test $[2,15]$ was performed with the patient supine at $30^{\circ}$ and $80^{\circ}$ of flexion. The tibia was compressed into posterior with the foot was fixed as externally rotated $15^{\circ}$. The test was repeated at least two times on both $30^{\circ}$ and $80^{\circ}$ knee flexion. When the amount of increased posterolateral translation was larger than the contralateral side was defined as a positive sign. The dial test $[26,27]$ was performed in prone position with the knee flexed at $30^{\circ}$ and $80^{\circ}$. The tibia was rotated externally to assess the side to side difference. The test was considered positive when there is more than $10^{\circ}$ of external rotation in the injured knee compared to the uninjured knee.

\section{Radiological evaluation}

All knees underwent magnetic resonance imaging (MRI) examinations using a knee coil. In fact, most of the patients were coming to our consultation with MRI examinations already performed. These MRI examinations were evaluated by experienced musculoskeletal radiologists and all their reports were reviewed. As one of the patient selection process, those who showed on MRI cruciate ligament injury or abnormal findings of other knee joint structures, such as other meniscal tears or chondral lesions were excluded. 


\section{Arthroscopic evaluation}

Based on the results of the clinical history, the physical examination and radiological evaluation, those corresponding to type B and/or grade I/II (according to diagnostic criteria in Tables 1, and 2) were clinically diagnosed as isolated PLC injury. All those patients have failed previous conservative treatment including all physical therapy modalities. In all patients, arthroscopic evaluation was performed in supine position. The knee was placed at $90^{\circ}$ of flexion with a foot support to allow for full range of knee motion. Firstly, a thorough physical examination was performed under anesthesia including varus stress test, posterolateral drawer test, and dial test and compared to contralateral knee in all patients. Then, a standard diagnostic arthroscopy was performed with a $30^{\circ}$ arthroscope. The presence of a meniscal tear and its pattern were evaluated by probing the meniscal lesions and recorded. To proceed to the specific evaluation of the lateral meniscus and hiatus popliteus, the arthroscope was introduced through the anterolateral portal into the lateral gutter with the knee in full extension. In this position, the optical lens was rotated to allow for good visualization of the hiatus popliteus and the border of lateral tibial plateau. When the scope was able to be inserted into the hiatus popliteus itself and passed in front of the tendon from anterior to posterior, the "lateral drive-through test" was considered positive $[9,10]$ (Fig. 1a). Furthermore, when the cartilage border of the lateral tibial plateau was seen as large crescent shape, this sign was called the "crescent moon sign" (Fig. $1 \mathrm{~b})$. The presence of these signs was recorded in all patients. After this procedure, the stability of the lateral meniscus was systematically assessed by pulling on the posterior root, posterior horn, posterior and anterior part of the hiatus popliteus. When the lateral meniscus could be subluxated to the middle of the lateral femorotibial compartment (Fig. 1c), it was diagnosed as hypermobile lateral meniscus. A $70^{\circ}$ arthroscope was never used in any of these cases.

\section{Results}

A total of 71 patients diagnosed as an isolated PLC injury underwent arthroscopic procedures (35 males and 36 females, 72 knees) in this study. Patient characteristics are shown in detail in Table 3. The mean height was $175.4 \pm 9.2 \mathrm{~cm}$ (range: $161-191 \mathrm{~cm}$ ) and the mean weight was $70.2 \pm 14.3 \mathrm{~kg}$ (range: $45-100 \mathrm{~kg}$ ). The mean patient age was $32.1 \pm 12.8$ years (range: $14-73$ years). The mean duration between trauma and arthroscopic evaluation was $16.7 \pm 23.5$ months. Fifty-six patients $(77.8 \%)$ were to low energy sports related injuries (Ski 14, Football 4, Ice-hockey 4) and twelve (21.4\%) were minor knee sprain in daily living or uncertain mechanism, sometimes just tripping. The varus stress test in extension, posterolateral drawer test at $30^{\circ}$ of flexion, and the dial test at $30^{\circ}$ of flexion were positive in all patients (Table 4).

In terms of arthroscopic findings, the lateral drivethrough tests positive was seen in 69 patients (95.8\%). Among 72 knees diagnosed as the isolated PLC injury, hypermobile lateral meniscus was found in all knees (Table 4).
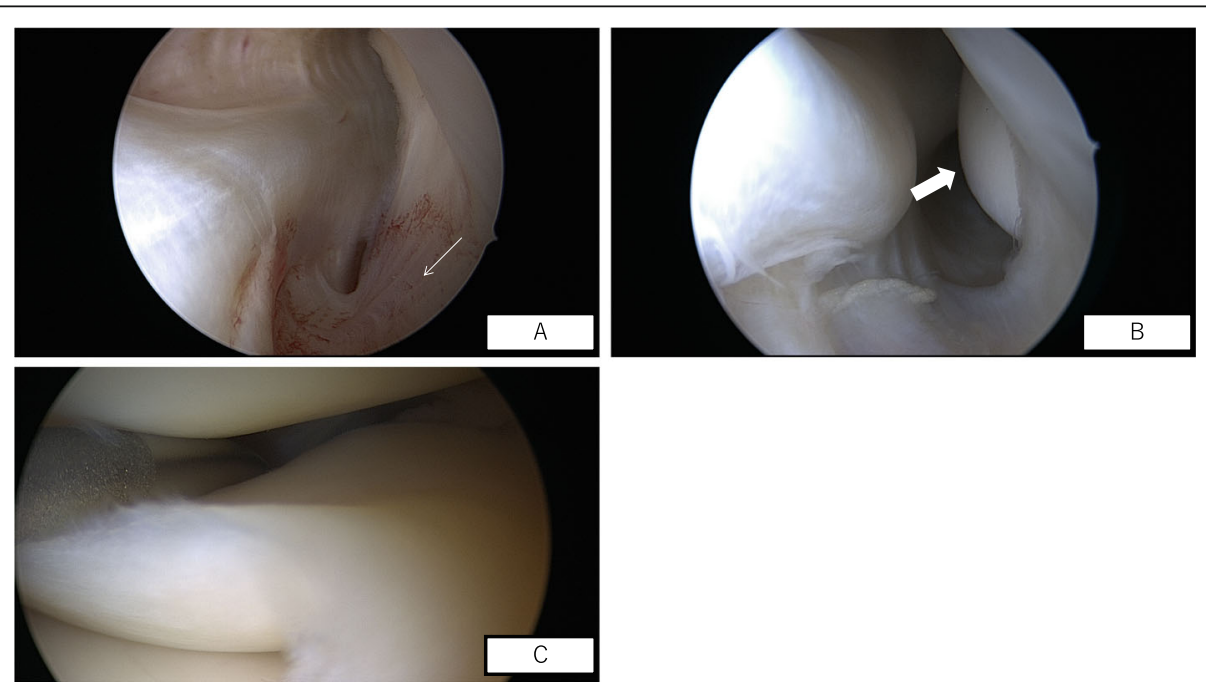

Fig. 1 a. Drive through test positive on a right knee. b. Crescent moon sign. c. hypermobile lateral meniscus on a left knee. Arthroscopic findings of the right knee; the image is viewed from the anterolateral portal. a: Arthroscopic view, lateral gutter, right knee, of torn popliteomeniscal fascicles (white narrow arrow). b: Arthroscopic view, lateral gutter, right knee, showing "crescent moon sign" (white broad narrow). c: Arthroscopic view of disruption of the popliteomeniscal fascicles of the lateral meniscus in a left knee. Significant subluxation of the lateral meniscus can be demonstrated by anteromedial traction applied by a surgical probe 
Table 3 Demographic characteristics of the study cohort

\begin{tabular}{ll}
\hline Number of cases/knees & $\mathbf{7 1 / 7 2}$ \\
\hline Age, years (range) & $32.1 \pm 12.8(14-73)$ \\
Sex (male/female) & $35 / 36$ \\
Right/Left knee & $25 / 47$ \\
$\begin{array}{l}\text { The mean duration between arthroscopic } \\
\text { diagnosis and trauma, month (range) }\end{array}$ & $16.7 \pm 23.5$ (1-180) \\
\hline
\end{tabular}

\section{Discussion}

The most important finding of this study was that all the patients diagnosed as isolated PLC injury showed a hypermobile LM with posterolateral rotational instability in our case series. Remarkably, during arthroscopy, a positive lateral drive through test was seen in 69/72 knees (95.8\%). This specific arthroscopic finding may help to prevent overlooking for isolated PLC injuries with hypermobile lateral meniscus and better detect this entity.

The association between a positive lateral drive through test and PLC structures injury have been investigated by Feng et al. in a cadaveric study. Positive lateral drive through test was present after the section of popliteofibular ligament and distal popliteus or after the section of medial/posteromedial structures (sMCL, deep MCL and POL) or cruciate ligaments (ACL and PCL) [10]. In their study, individual sectioning of any single structure of the PLC could not lead to positive lateral drive through test. In our patients, injury of medial structures or cruciate ligaments has been excluded.

In previous studies, PLC injuries have been classified following two classifications: Fanelli and Larson and Hughston classification (Tables 1, and 2) [8, 15]. The PLC injury we report here might be classified as Fanelli type B injury or Hughston grade I/II injury. Conservative therapy may be a good treatment option despite the lack of solid evidence [32]. In a few studies, good outcomes have been reported after non-operative treatment for grade I and II injuries, however residual lateral laxity was commonly noted in grade II injuries $[18,19]$. All patients included in this study have failed with conservative treatment prior to arthroscopy and/or surgical

Table 4 The positive rates of physical examinations and arthroscopic findings

\begin{tabular}{ll}
\hline Physical examinations & \\
\hline Varus stress test & $\mathbf{7 2 / 7 2 ( 1 0 0 \% )}$ \\
\hline Posterolateral drawer test & $72 / 72(100 \%)$ \\
Dial test & $72 / 72(100 \%)$ \\
Arthroscopic findings & \\
Drive through test & $69 / 72(95.8 \%)$ \\
\hline
\end{tabular}

treatment, who were still complaining of posterolateral pain and instability.

Previous reports have showed that injuries of PMFs structures can provoke hypermobile lateral meniscus. Hypermobile lateral meniscus is a relatively uncommon condition and most of the patients typically have no history of associated trauma [11, 14, 28]. Most patients complained of catching, clicking, or sometimes locking in hyperextension as typical symptoms [17], however a few patients complained only of pain without mechanical symptoms [38]. As far as we know, there are no study that investigated this concomitant lesion between grade II PLC injury and hypermobile lateral meniscus.

One of the factors that contributed to the concomitant hypermobile LM in all of our cases was likely a complication of PMF injury. Some anatomical studies showed the strong association between PMFs and hypermobile lateral meniscus. The posterior horn of the lateral meniscus has only a loose attachment to the capsule, which is constructed by the posterior superior popliteomeniscal fascicle and anterior inferior popliteomeniscal fascicle [5]. The superior fascicle arises from the medial fibers of the aponeurosis of the popliteus tendon, whereas the inferior fascicle is a coronary ligament that extends from the meniscus to the edge of the tibia [16]. In particular, the anteroinferior fascicle had a greater degree of control over lateral meniscus [36]. Therefore, even minimal trauma can result in complete failure of these structures and load to subluxation of lateral meniscus in certain subjects [11], which may lead to the pain in the lateral compartment of the knee and mechanical symptoms such as locking and giving way $[13,31]$.

La Prade et al. [22] reported six patients with isolated tears of the PMFs who had lateral joint line knee pain. All of those patients showed hypermobile lateral meniscus due to tears of the PMFs on arthroscopic examination. In their study, open repair surgeries were performed as complete resolution of their lateral compartment knee pain. Moreover, it was also reported that the "figure-4 test" was positive in all patients as clinical examination, which should be useful to diagnosis isolated PMFs tear. However, it was not clearly mentioned if rotational instability was present in their cohort. Simonian et al. [34] also reported about three cases of lateral meniscus subluxation and they identified a disruption of the fascicular attachments between the popliteus tendon and lateral meniscus as the cause of meniscus instability. In a biomechanical study by Simonian et al. [33], the disruption of the PMFs showed abnormal meniscal motion of approximately doubled compared to intact condition. Therefore, disruption of the PMFs can provoke hypermobile lateral meniscus. Additionally, several therapeutic studies showed that surgical repair restored meniscal stable motion and no recurrences of symptoms were 
observed [17, 28, 38], which also would support the correlation between symptomatic isolated PLC injury and hypermobile lateral meniscus.

Regarding the contribution of MRI in diagnosing the entity, we and others have to admit that MRI is not very useful except if a specific plan is used to acquire the images [30]. In previous reports, popliteomeniscal fascicle tears were often difficult to recognize and diagnose with MRI examinations $[22,31]$. Another study by Simonian et al. reported about 3 patients whose were found to have unstable popliteomeniscal fascicle tears at the time of surgery and had normal MRI findings [34]. Suganuma et al. evaluated popliteomeniscal fascicle in MRI findings of 238 knees including 16 knees with recurrent subluxation of the LM and 215 healthy knees [35]. In their study, abnormal findings of superiorinferior popliteomeniscal fascicles and inferioranterior popliteomeniscal fascicles were noted in $40 \%$ and $26 \%$ of the control group respectively; and in $100 \%$ of the LM hypermobility group. However, the acquisition of their MRI images was performed in the anteromedial-to-posterolateral directed $45^{\circ}$ oblique coronal plan, which is not routinely performed in most of institutions. Finally, MRI is a static examination and may just not be appropriate to accurately diagnose LM and posterolateral rotational instability. Therefore, history of the patient and clinical examination are key factors to diagnose this entity.

This study has some limitations. First, the number of patients was small, and the results might vary from those of studies with larger sample size. Secondary, this was a retrospective study which reported characteristic findings of this combined lesion, but this is the first study that reports about the concomitant injury between hypermobile LM and abnormal rotational PLC instability. Finally, there may be asymptomatic hypermobile lateral meniscus or lateral drive through test positive as normal variant in some cases. However, all patient of this study had symptoms and clinical signs as well as abnormal findings during the arthroscopic evaluation. A better understanding of the clinical presentation and the characterization of the arthroscopic examination would help to prevent oversight and provide the proper treatment for isolated PLC injuries with hypermobile LM.

\section{Conclusion}

Isolated PLC injury may comprise lateral meniscal hypermobility with rotational PLC instability and may present pain and instability of the posterolateral compartment of the knee. It is crucial to acknowledge this entity, which patient history, sometimes a minor sport and/or domestic accident, specific clinical examination and meticulous arthroscopic evaluation (including lateral drive through test and palpation of LM) can be key roles.

\section{Abbreviations}

PLC: Posterolateral corner; LM: Lateral meniscus; PMF: Popliteomeniscal fasicle; MRI: Magnetic resonance imaging; AS: Arthroscopy

\section{Acknowledgements}

Not applicable.

\section{Authors' contributions}

M.J. conceived of the presented idea. M.J. and D.V. developed the theory and performed the computations. G.K. and M.J. verified the analytical methods. M.J. encouraged G.K. to investigate this study and supervised the findings of this work. G.K. designed the study and wrote the initial draft of the manuscript. D.V. contributed to analysis and interpretation of data and assisted in the preparation of the manuscript. All other authors have contributed to data collection and interpretation, and critically reviewed the manuscript. M.J. conceived of the study and was in charge of overall direction and planning. All authors approved the final version of the manuscript and agree to be accountable for all aspects of the work in ensuring that questions related to the accuracy or integrity of any part of the work are appropriately investigated and resolved. The author(s) read and approved the final manuscript.

\section{Authors' information}

M.J. is a specialist of knee arthroscopy who has experience performing more than 10000 anterior cruciate ligament reconstructions.

\section{Funding}

This research did not receive any specific grant from funding agencies in the public, commercial, or not-for-profit sectors.

\section{Availability of data and materials}

The datasets during and/or analyzed during the current study available from the corresponding author on reasonable request.

\section{Ethics approval and consent to participate}

This study was approved by our institutional review board. Written informed consent was obtained from the patients for publication of this case series and accompanying images.

\section{Consent for publication}

Written informed consent was obtained from the patients for publication of this case series and accompanying images.

\section{Competing interests}

The authors declare that they have no competing interests.

Received: 2 September 2020 Accepted: 18 November 2020

Published online: 01 December 2020

\section{References}

1. Aman ZS, DePhillipo NN, Storaci HW, Moatshe G, Chahla J, Engebretsen L, LaPrade RF (2019) Quantitative and qualitative assessment of Posterolateral meniscal anatomy: defining the popliteal Hiatus, Popliteomeniscal fascicles, and the lateral Meniscotibial ligament. Am J Sports Med 47(8):1797-1803. https://doi.org/10.1177/0363546519849933

2. Angelini FJ, Bonadio MB, Helito CP, da Mota E Albuquerque RF, Pécora JR, Camanho GL (2014) Description of the posterolateral rotatory drawer maneuver for the identification of posterolateral corner injury. Arthrosc Tech 3(2):e299-e302. https://doi.org/10.1016/j.eats.2014.01.008

3. Chahla J, Moatshe G, Dean CS, LaPrade RF (2016) Posterolateral corner of the knee: current concepts. Arch bone Jt Surg 4(2):97-103. https://doi.org/ 10.22038/ABJS.2016.6435

4. Chahla J, Murray IR, Robinson J, Lagae K et al (2019) Posterolateral corner of the knee: an expert consensus statement on diagnosis, classification, treatment, and rehabilitation. Knee Surg sports Traumatol Arthrosc 27(8): 2520-2529. https://doi.org/10.1007/s00167-018-5260-4

5. Cohn AK, Mains DB (1979) Popliteal hiatus of the lateral meniscus. Anatomy and measurement at dissection of 10 specimens. Am J Sports Med 7(4): 221-226. https://doi.org/10.1177/036354657900700402

6. Corea JR, Moussa M, Al Othman A (1994) McMurray's test tested. Knee Surg sports Traumatol Arthroscop 2(2):70-72. https://doi.org/10.1007/BF01476474 
7. Crespo B, James EW, Metsavaht L, LaPrade RF (2014) Injuries to posterolateral corner of the knee: a comprehensive review from anatomy to surgical treatment. Rev bras Ortop 50(4):363-370. https://doi.org/10.1016/j. rboe.2014.12.008

8. Fanelli GC, Larson RV (2002) Practical management of posterolateral instability of the knee. Arthroscopy 18(2):1-8. https://doi.org/10.1053/jars.2002.31779

9. Feng $H$, Zhang $H$, Hong L, Wang XS, Zhang J (2009) The "lateral gutter drive-through" sign: an arthroscopic indicator of acute femoral avulsion of the popliteus tendon in knee joints. Arthroscopy 25(12):1496-1499. https:// doi.org/10.1016/j.arthro.2009.08.005

10. Feng $\mathrm{H}$, Song $\mathrm{G}$, Shen J et al (2014) The "lateral gutter drive-through" sign revisited: a cadaveric study exploring its real mechanism based on the individual posterolateral structure of knee joints. Arch Orthop trauma Surg 134:1745-1751. https://doi.org/10.1007/s00402-014-2100-y

11. Garofalo R, Kombot C, Borens O, Djahangiri A, Mouhsine E (2005) Locking knee caused by subluxation of the posterior horn of the lateral meniscus. Knee Surg sports Traumatol Arthrosc 13(7):569-571. https://doi.org/10.1007/ s00167-004-0581-x

12. Geeslin AG, Moulton SG, LaPrade RF (2016) A systematic review of the outcomes of Posterolateral corner knee injuries, part 1: surgical treatment of acute injuries. Am J sports med 44(5):1336-1342. https://doi.org/10.1177/ 0363546515592828

13. Guimaraes JB, Facchetti L, Schwaiger BJ, Gersing AS, Li X, Link TM (2018) Natural evolution of popliteomeniscal fascicle tears over 2 years and its association with lateral articular knee cartilage degeneration in patients with traumatic anterior cruciate ligament tear. Eur Radiol 28(8):3542-3549. https://doi.org/10.1007/s00330-017-5279-9

14. Higuchi H, Kimura M, Kobayashi A, Hatayama K, Takagishi K (2004) A novel treatment of hypermobile lateral meniscus with monopolar radiofrequency energy. Arthroscopy 20(2):1-5. https://doi.org/10.1016/j.arthro.2004.04.011

15. Hughston JC, Norwood LA Jr (1980) The posterolateral drawer test and external rotational recurvatum test for posterolateral rotatory instability of the knee. Clin Orthop Relat Res 147:82-87

16. Johnson R, De Smet A (1999) MR visualization of the popliteomeniscal fascicles. Skeletal Radiol 28(10):561-566. https://doi.org/10.1007/ s002560050619

17. Kamiya T, Suzuki T, Otsubo H, Kuroda M, Matsumura T, Kubota C, Yamashita T (2018) Midterm outcomes after arthroscopic surgery for hypermobile lateral meniscus in adults: restriction of paradoxical motion. J Orthop Sci 23(6):1000-1004. https://doi.org/10.1016/j.jos.2018.06.003

18. Kannus P (1989) Nonoperative treatment of grade II and III sprains of the lateral ligament compartment of the knee. Am J Sports Med 17(1):83-88. https://doi.org/10.1177/036354658901700114

19. Krukhaug Y, Mølster A, Rodt A, Strand T (1998) Lateral ligament injuries of the knee. Knee Surg Sports Traumatol Arthrosc 6(1):21-25. https://doi.org/ $10.1007 /$ s001670050067

20. LaPrade RF (1997) Arthroscopic evaluation of the lateral compartment of knees with grade 3 posterolateral knee complex injuries. Am J Sports Med 25(5):596-602. https://doi.org/10.1177/036354659702500502

21. LaPrade RF, Wentorf F (2002) Diagnosis and treatment of posterolateral knee injuries. Clin Orthopaedics Related Res (402):110-121. https://doi.org/ 10.1097/00003086-200209000-00010

22. LaPrade RF, Konowalchuk BK (2005) Popliteomeniscal fascicle tears causing symptomatic lateral compartment knee pain: diagnosis by the figure-4 test and treatment by open repair. Am J Sports Med 33(8):1231-1236. https:// doi.org/10.1177/0363546504274144

23. LaPrade RF, Wentorf FA, Fritts H, Gundry C, Hightower D (2007) A prospective magnetic resonance imaging study of the incidence of posterolateral and multiple ligament injuries in acute knee injuries presenting with a hemarthrosis. Arthroscopy 23(12):1341-1347. https://doi. org/10.1016/j.arthro.2007.07.024

24. Lee SY, Choi YJ, Park HJ, Kook SH, Kang KA, Kim MS, Kwon HJ, Ahn JH (2019) Types of posterolateral corner injury associated with both bundle and selective-bundle ACL tears. Acta Radiol May 1:284185119842833. https://doi.org/10.1177/0284185119842833

25. Moulton SG, Geeslin AG, LaPrade RF (2016) A systematic review of the outcomes of Posterolateral corner knee injuries, part 2: surgical treatment of chronic injuries. Am J Sports Med 44(6):1616-1623. https://doi.org/10.1177/ 0363546515593950

26. Norris R, Kopkow C, McNicholas MJ (2018) Interpretations of the dial test should be reconsidered. A diagnostic accuracy study reporting sensitivity, specificity, predictive values and likelihood ratios. J ISAKOS: Joint Disorders \& Orthopaedic Sports Medicine 3:198-204

27. Noyes FR, Stowers SF, Grood ES, Cummings J, VanGinkel LA (1993) Posterior subluxations of the medial and lateral tibiofemoral compartments. An in vitro ligament sectioning study in cadaveric knees. Am J Sports Med 21(3):407-414. https://doi.org/10.1177/036354659302100314

28. Ohtoshi K, Kimura M, Kobayashi Y, Higuchi H, Kikuchi S (2004) Arthroscopic thermal shrinkage for hypermobile lateral meniscus. Am J Sports Med 32(5): 1297-1301. https://doi.org/10.1177/0363546503262185

29. Pacheco RJ, Ayre CA, Bollen SR (2011) Posterolateral corner injuries of the knee: a serious injury commonly missed. J bone joint Surg Br 93(2):194-197. https://doi.org/10.1302/0301-620X.93B2.25774

30. Sakai H, Sasho T, Wada Y, Sano S, Iwasaki J, Morita F, Moriya H (2006) MRI of the popliteomeniscal fasciculi. Am J Roentgenol 186(2):460-466. https://doi. org/10.2214/AJR.04.0068

31. Shin HK, Lee HS, Lee YK, Bae KC, Cho CH, Lee KJ (2012) Popliteomeniscal fascicle tear: diagnosis and operative technique. Arthrosc tech 1(1):e101-e106

32. Shon OJ, Park JW, Kim BJ (2017) Current concepts of Posterolateral corner injuries of the knee. Knee Surg Relat res 29(4):256-268. https://doi.org/10. 5792/ksrr.16.029

33. Simonian PT, Sussmann PS, van Trommel M, Wickiewicz TL, Warren RF (1997) Popliteomeniscal fasciculi and lateral meniscal stability. Am J Sports Med 25(6):849-853. https://doi.org/10.1177/036354659702500620

34. Simonian PT, Sussmann PS, Wickiewicz TL, Potter HG, van Trommel M, Weiland-Holland S, Warren RF (1997) Popliteomeniscal fasciculi and the unstable lateral meniscus: clinical correlation and magnetic resonance diagnosis. Arthroscopy 13(5):590-596. https://doi.org/10.1016/s07498063(97)90185-7

35. Suganuma J, Mochizuki R, Inoue $Y$, Yamabe E, Ueda $Y$, Kanauchi T (2012) Magnetic resonance imaging and arthroscopic findings of the popliteomeniscal fascicles with and without recurrent subluxation of the lateral meniscus. Arthroscopy 28(4):507-516. https://doi.org/10.1016/ j.arthro.2011.08.311

36. Sussmann SP, Wickiewicz T, Warren R (2001) Development of the popliteomeniscal fasciculi in the fetal human knee joint. Arthroscopy 17(1): 14-18. https://doi.org/10.1053/jars.2001.19653

37. Temponi EF, de Carvalho Junior LH, Saithna A, Thaunat M, Sonnery-Cottet B (2017) Incidence and MRI characterization of the spectrum of posterolateral corner injuries occurring in association with $A C L$ rupture. Skeletal Radiol 46(8):1063-1070. https://doi.org/10.1007/s00256-017-2649-y

38. Van Steyn MO, Mariscalco MW, Pedroza AD et al $(2016,24)$ The hypermobile lateral meniscus: a retrospective review of presentation, imaging, treatment, and results. Knee Surg sports Traumatol Arthrosc (5): 1555-1559. https://doi.org/10.1007/s00167-014-3497-0

\section{Publisher's Note}

Springer Nature remains neutral with regard to jurisdictional claims in published maps and institutional affiliations.

\section{Submit your manuscript to a SpringerOpen ${ }^{\circ}$ journal and benefit from:}

- Convenient online submission

- Rigorous peer review

- Open access: articles freely available online

- High visibility within the field

- Retaining the copyright to your article

Submit your next manuscript at $>$ springeropen.com 